\title{
Optimization of Mycelial Biomass Production in Submerged Culture Fermentation of Pleurotus flabellatus Using Response Surface Methodology
}

\author{
Shaiful Azuar Mohamad1*, Mat Rasol Awang1, Rosnani Abdul Rashid1, Liew Siew Ling2, \\ Fauzi Daud², Aidil Abdul Hamid², Rahayu Ahmad², Wan Mohtar Wan Yusoff ${ }^{2}$ \\ ${ }^{1}$ Agrotechnology and Biosciences Division, Malaysian Nuclear Agency, Bangi, Malaysia \\ ${ }^{2}$ Faculty of Science and Technology, Universiti Kebangsaan Malaysia, Bangi, Malaysia \\ Email: azuar@nuclearmalaysia.gov.my
}

Received 2 May 2015; accepted 22 June 2015; published 26 June 2015

Copyright @ 2015 by authors and Scientific Research Publishing Inc.

This work is licensed under the Creative Commons Attribution International License (CC BY).

http://creativecommons.org/licenses/by/4.0/

(c) (i) Open Access

\section{Abstract}

The factors selected to optimize the productivity of Pleurotus flabellatus biomass in $250 \mathrm{ml}$ working volume Erlenmeyer flask were agitation rate, initial $\mathrm{pH}$ value and incubation temperature. The central composite design was applied to study the significant factors and the interactions between the chosen factors, if present. The Design Expert software generated 20 runs. The optimized conditions obtained were as follows: the agitation rate of $129.8 \mathrm{rpm}$, incubation temperature at $27.8^{\circ} \mathrm{C}$, and initial $\mathrm{pH}$ of 6.06. The optimized conditions tripled the productivity at the range of $980-1040$ $\mathrm{mg} / \mathrm{litre} /$ day compared to the initial rate productivity at $310 \mathrm{mg} / \mathrm{litre} /$ day. From the quadratic equation,the agitation rate, temperature and the interaction between agitation rate and temperature were found to be significant $(p<0.05)$. At optimum conditions, the experimental data supported the theoretical estimate.

\section{Keywords}

Submerged Culture Fermentation, Response Surface Methodology, Mushroom Production

\section{Introduction}

From our preliminary study, the mycelium of $P$. flabellatus (local isolate) contained $\beta$-glucan. Several resear-

*Corresponding author.

How to cite this paper: Mohamad, S.A., et al. (2015) Optimization of Mycelial Biomass Production in Submerged Culture Fermentation of Pleurotus flabellatus Using Response Surface Methodology. Advances in Bioscience and Biotechnology, 6, 419-426. http://dx.doi.org/10.4236/abb.2015.66041 
chers have reported the importance of $\beta$-glucan as an immunomodulation compound and its inhibitory effects on certain tumor growth in animal and human [1] [2]. Currently, no paper has reported on the production of $\beta$-glucan using $P$. flabellatus in submerged culture fermentation (SCF). This paper reports a methodology to enhance productivity of $\beta$-glucan using RSM.

The optimization by means of RSM was chosen in this study as it allows the interaction of several parameters to be studied. The three parameters chosen for the optimization study were based on several references for agitation rate, incubation temperature, and initial $\mathrm{pH}$ [3]-[6]. Thus, the starting values of RSM were; the agitation rate from $50 \mathrm{rpm}$ to $130 \mathrm{rpm}$, temperature from $20^{\circ} \mathrm{C}$ to $30^{\circ} \mathrm{C}$, and $\mathrm{pH}$ from 5 to 7 .

SCF has potential to shorten the fermentation time to produce the target mycelium containing $\beta$-glucan. Using conventional solid state fermentation the production of fruit body can take from 2 to 3 months but SCF can reduce the time to approximately 1 month.

\section{Materials and Methods}

\subsection{Microorganisms, Media and Cultivation}

The stock culture of $P$. flabellatus, was maintained on potato dextrose agar (PDA) slants sub-cultured every 3 months. The mycelium in petri dish were transferred to the Erlenmeyer flask by punching out $1 \mathrm{~cm}$ of the agar plate culture with a sterilized blade. The seed culture was grown in $500 \mathrm{ml}$ Erlenmeyer flask containing $250 \mathrm{ml}$ media (Mushroom Complete Media) MCM comprises of $20 \mathrm{~g} / \mathrm{l}$ glucose, $2 \mathrm{~g} / \mathrm{l}$ meat peptone, $2 \mathrm{~g} / \mathrm{l}$ yeast extract, $0.46 \mathrm{~g} / \mathrm{l} \mathrm{KH} \mathrm{PO}_{4}, 1 \mathrm{~g} / \mathrm{l} \mathrm{K} \mathrm{HPO}_{4}, 0.5 \mathrm{~g} / \mathrm{l} \mathrm{MgSO}_{4} \cdot 7 \mathrm{H}_{2} \mathrm{O}$.

\subsection{Response Surface Methodology (RSM)}

The origin of RSM can be traced to the Taylor's function which assumed that any function can be expressed in its generic equation. Taylor's function, for a second order model with three input variables can be expressed as follows:

$$
F(X)=F\left(X_{0}\right)+a X_{1}+b X_{2}+c X_{3}+d X_{1}^{2}+e X_{2}^{2}+f X_{3}^{2}+g X_{1} X_{2}+h X_{1} X_{3}+i X_{2} X_{3}
$$

here $a, b, \ldots i$ are coefficients.

A Central Composite Rotatable Design was used to allocate treatment combinations involving the three parameters studied, namely, incubation temperature, agitation rate and initial $\mathrm{pH}$. Based on the Design Expert software (Version 6, Stat-Ease Inc., Minneapolis, USA) statistical package, the experimental model only generated 20 experiments because it only generated the minimum number of experiments that need to be done to solve the equations statistically. The experiment were done in triplicate to get the biomass from the submerged culture fermentation.

\section{Results and Discussion}

\section{1. pH Determinaton Range}

The highest agitation rate achievable was $130 \mathrm{rpm}$. Therefore, the three levels of agitation rate tested were 50, 90 and $130 \mathrm{rpm}$. For pH, an experiment was done to determine the response (Figure 1) and a value from $\mathrm{pH} 5$ to 7 was chosen. Initial biomass screening results obtained from at $50 \mathrm{rpm}$, uncontrolled temperature and $\mathrm{pH}$ yield the productivity to be $310.9 \mathrm{mg} /$ litre/day, using MCM media and taking 10 days as fermentation days (unpublished results).

\subsection{RSM Experimental Results and Analysis}

Table 1 shows the 20 treatment combinations studied using central composite design and their response for mycelium mass as well as the theoretical response values. The ranges of parameters are shown in coded values. A second-order regression model was applied to analyse the response data obtained.

The statistical significance of the second-order model was checked by F-test, and the analysis of variance (ANOVA) in Table 2 showed that the model is highly signifant, with a low probability value (P model, $\mathrm{F}<$ $0.0001)$. The high value of coefficient of determination $\left(R^{2}\right)$ shown as 0.965 indicated a close agreement between experimental results and theoretical values. The adj $\mathrm{R}^{2}$ (adjusted determinant coefficient) indicated that 


\section{$\mathrm{pH}$ determination range}

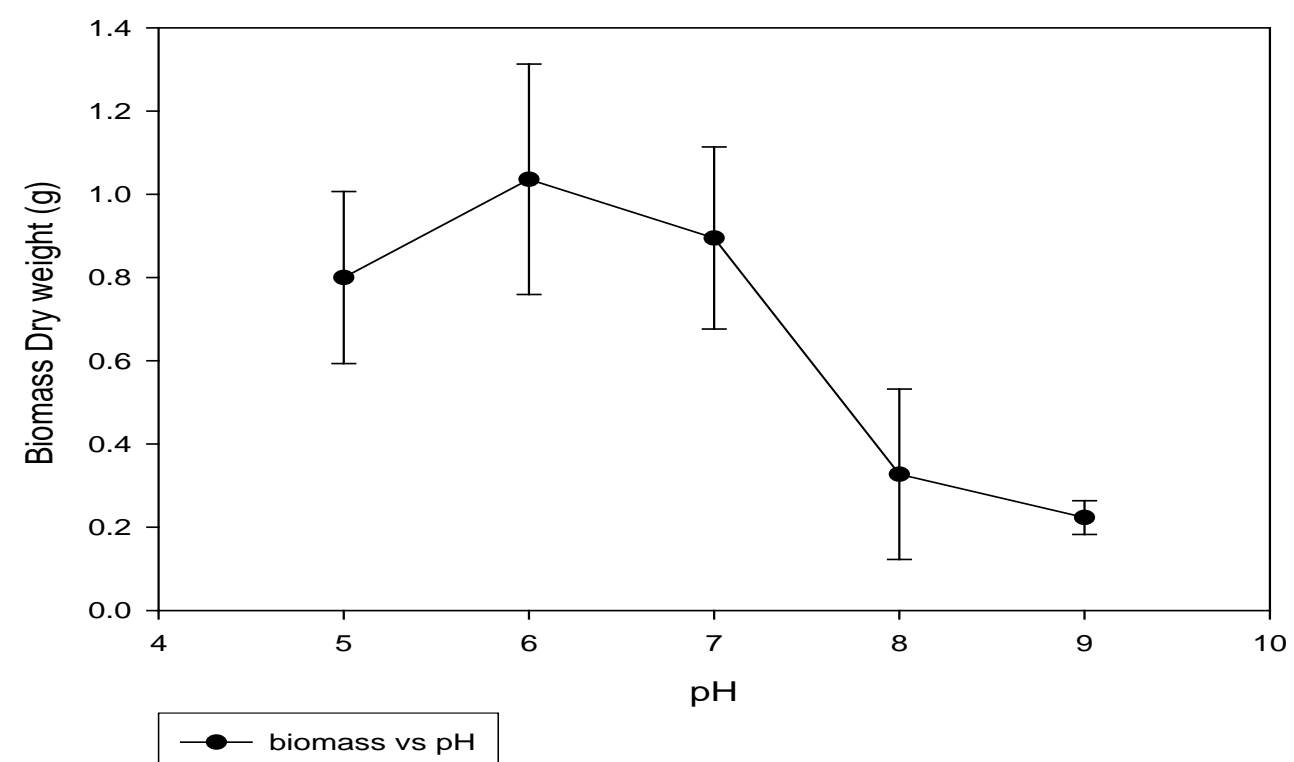

Figure 1. Effect of $\mathrm{pH}$ on mycelial biomass dry weight at $25^{\circ} \mathrm{C}, 100 \mathrm{rpm}$.

Table 1. Experimental central composite design (CCD) and the response of mycelium mass.

\begin{tabular}{|c|c|c|c|c|c|c|}
\hline \multirow{2}{*}{ Run } & \multirow{2}{*}{ Block } & \multicolumn{3}{|c|}{ Coded value } & \multicolumn{2}{|c|}{ Mycelium mass (g) } \\
\hline & & Agitation rate & Temp & $\mathrm{pH}$ & Response & Predicted value \\
\hline 1 & 1 & 0 & 0 & 0 & 0.77 & 0.93 \\
\hline 2 & 1 & -1 & 0 & 0 & 0.35 & 0.49 \\
\hline 3 & 1 & 1 & -1 & 1 & 1.74 & 1.68 \\
\hline 4 & 1 & -1 & 1 & -1 & 0.19 & 0.25 \\
\hline 5 & 1 & 0 & 1 & 0 & 1.29 & 1.07 \\
\hline 6 & 1 & -1 & -1 & -1 & 0.07 & -0.09 \\
\hline 7 & 1 & -1 & -1 & 1 & 0.21 & 0.18 \\
\hline 8 & 1 & 1 & 1 & -1 & 2.54 & 2.56 \\
\hline 9 & 1 & 0 & 0 & 0 & 0.74 & 0.93 \\
\hline 10 & 1 & 0 & 0 & -1 & 0.63 & 0.71 \\
\hline 11 & 1 & 0 & 0 & 0 & 0.84 & 0.93 \\
\hline 12 & 1 & 1 & -1 & -1 & 1.56 & 1.56 \\
\hline 13 & 1 & 0 & 0 & 0 & 0.94 & 0.93 \\
\hline 14 & 1 & 1 & 0 & 0 & 2.5 & 2.4 \\
\hline 15 & 1 & -1 & 1 & 1 & 0.4 & 0.39 \\
\hline 16 & 1 & 1 & 1 & 1 & 2.41 & 2.56 \\
\hline 17 & 1 & 0 & 0 & 0 & 1.08 & 0.93 \\
\hline 18 & 1 & 0 & 0 & 1 & 0.89 & 0.84 \\
\hline 19 & 1 & 0 & -1 & 0 & 0.21 & 0.18 \\
\hline 20 & 1 & 0 & 0 & 0 & 1.25 & 0.93 \\
\hline
\end{tabular}

Temperature $\left(20^{\circ} \mathrm{C}, 25^{\circ} \mathrm{C}, 30^{\circ} \mathrm{C}\right), \mathrm{pH}(5,6,7)$ and agitation rate (50 rpm, $\left.90 \mathrm{rpm}, 130 \mathrm{rpm}\right)$. 
96.5\% of the variability in the response could be explained by the model. A reasonably low value 19.46 of coefficient of variation (c.v) indicated a fairly good degree of precision and reasonably good deal of reliability of the experimental values. The lack-of-fit is not significant $(P=0.4728)$, indicating that the model equation was adequate for predicting the biomass production. The probability value smaller than $0.05(P<0.05)$ for the $x_{1}$ (shaking rate), $x_{2}$ (temperature), $x_{1}^{2}$ (product of shaking rate), $x_{1} x_{2}$ (interaction between shaking rate and temperature) indicated that these terms affected the biomass production significantly (Table 3 ).

The polynomial model for biomass yield $\mathrm{Y}_{\text {biomass }}$ was expressed by the full equation below.

$$
\begin{aligned}
Y_{\text {biomass }}= & 0.93+0.95 x_{1}+0.30 x_{2}+0.0660 x_{3}+0.52 x_{1}^{2}-0.16 x_{2}^{2}-0.15 x_{3}^{2} \\
& +0.17 x_{1} x_{2}-0.037 x_{1} x_{3}-0.030 x_{2} x_{3}
\end{aligned}
$$

The equation reveals that the agitation rate $\left(x_{1}\right)$ had the most significant effect on $Y_{\text {biomass }}$ as it had the largest coefficient followed by temperature $\left(x_{2}\right)$. Positive coefficients indicated an increase in parameters will increase the biomass production. The initial $\mathrm{pH}$ value $\left(x_{3}\right)$ does not significantly affect the yield. The $\mathrm{pH}$ is not significant for the biomass production. The only significant interaction towards the response is between agitation rate $\left(x_{1}\right)$ and temperature $\left(x_{2}\right)$.

The following 2D and 3D graphs can also highlight the interaction between variables and its effect towards the biomass production. From Figure 2, the biomass increased as the agitation rate increase. At low agitation rate, the increase in temperature results in only a small increase in biomass production. At higher agitation rate, biomass production increases rapidly when temperature increases. In Figure 3, the agitation rate affect the biomass significantly but $\mathrm{pH}$ does not affect the biomass at low or high RPM. Figure 4 showed that the optimum $\mathrm{pH}$ lies in the middle of the $\mathrm{pH}$ range taken and the optimum temperature lies at the higher range of temperature. These values were determined at the optimization section.

Table 2. Analysis of variance for the second-order regression model of biomass production.

\begin{tabular}{cccccc}
\hline Source & Sum of squares & d.f. & Mean square & F-value & Probability $\left(\mathrm{P}^{\circ}\right)>\mathrm{F}$ \\
\hline Model & 11.054 & 9 & 1.2282 & 30.556 & $<0.0001$ \\
Lack of fit & 0.207 & 5 & 0.0415 & 1.066 & 0.4728 \\
Pure error & 0.195 & 5 & 0.0389 & & \\
Corrected total & 11.456 & 19 & & \\
$\mathrm{R}^{2}=0.965$, adj- $\mathrm{R}^{2}=0.933$ & & & \\
\hline
\end{tabular}

c.v: 19.46 ; pred- $\mathrm{R}^{2}=0.814$; Significance value for $P<0.05$.

\begin{tabular}{|c|c|c|c|c|}
\hline Parameters & Sum of squares & Mean square & F-value & Prob $>$ F \\
\hline$x_{1}$ (agitation rate) & 9.0821 & 9.0821 & 225.950 & $<0.0001$ \\
\hline$x_{2}$ (temperature) & 0.9242 & 0.9242 & 22.992 & 0.0007 \\
\hline$x_{3}(\mathrm{pH})$ & 0.0436 & 0.0436 & 1.084 & 0.3224 \\
\hline$x_{1}^{2}$ & 0.7345 & 0.7345 & 18.274 & 0.0016 \\
\hline$x_{2}^{2}$ & 0.0688 & 0.0688 & 1.712 & 0.2200 \\
\hline$x_{3}^{2}$ & 0.0604 & 0.0604 & 1.502 & 0.2484 \\
\hline$x_{1} x_{2}$ & 0.2245 & 0.2245 & 5.584 & 0.0397 \\
\hline$x_{1} x_{3}$ & 0.0113 & 0.0113 & 0.280 & 0.6083 \\
\hline$x_{2} x_{3}$ & 0.0072 & 0.0072 & 0.179 & 0.6811 \\
\hline
\end{tabular}

Table 3. Results of regression analysis of second-order model for optimization of mycelium biomass. 

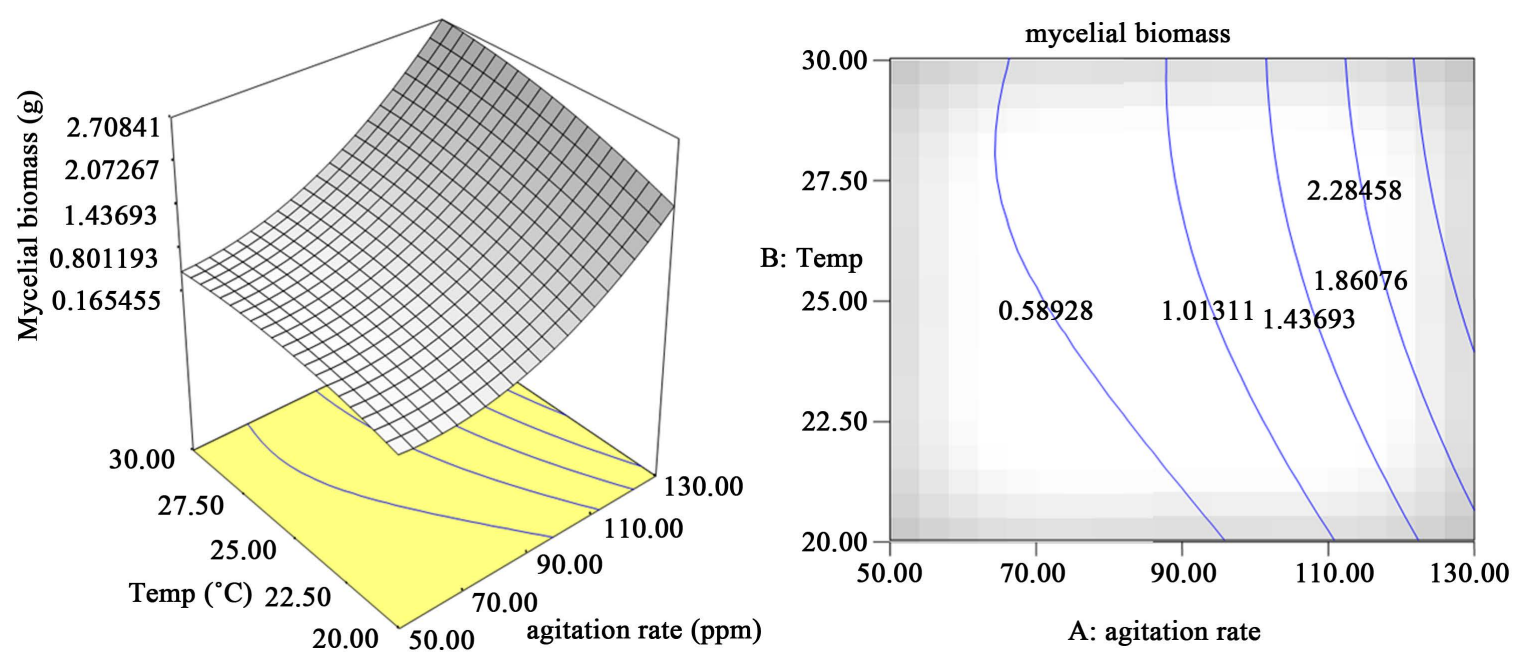

Figure 2. The response surface between temperature and agitation rate at constant $\mathrm{pH} 6.00$.
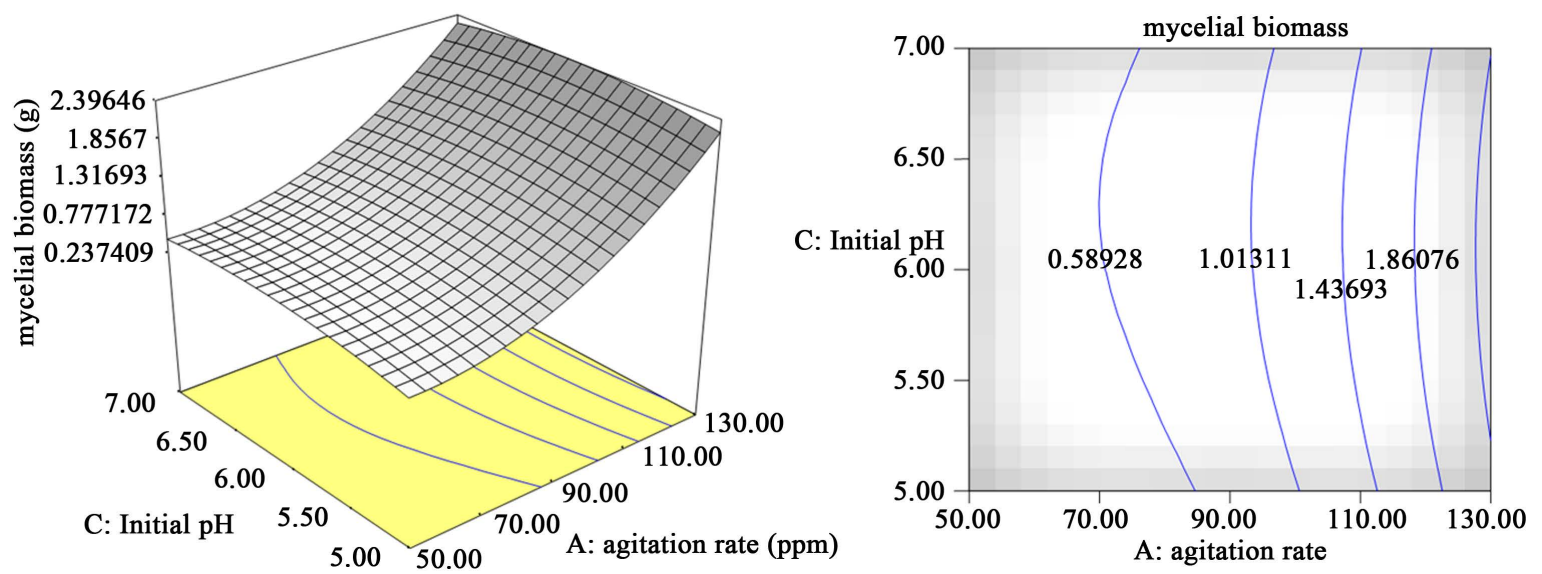

Figure 3. The response surface curve between $\mathrm{pH}$ and agitation rate at constant temperature $25^{\circ} \mathrm{C}$.

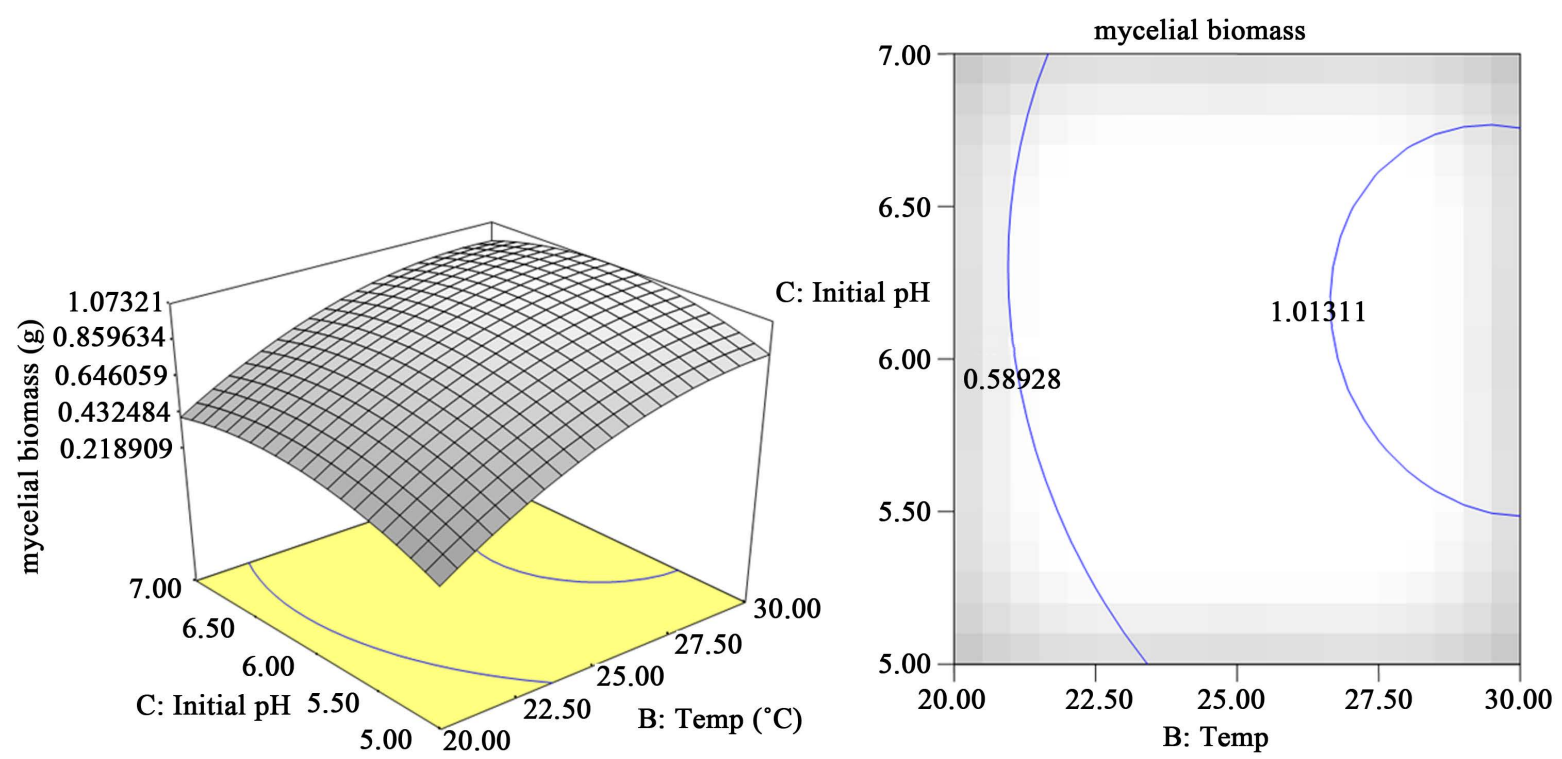

Figure 4. The response surface curve between $\mathrm{pH}$ and temperature at constant agitation rate $90 \mathrm{rpm}$. 


\subsection{Predicted Optimized Conditions of the Maximum Biomass from Theoretical Model and Its Validation Experiment}

There are 10 solutions offered by the software Design Expert as shown in Figure 5. The solutions of the shaking rate lies between $127.2 \mathrm{rpm}$ to $130 \mathrm{rpm}$, the temperature from $25.3^{\circ} \mathrm{C}$ to $29.8^{\circ} \mathrm{C}$ and the $\mathrm{pH}$ from 5 to 7 with different estimation of the biomass prediction. Since we want the shaking rate to be as maximum as possible and the initial $\mathrm{pH}$ to be 6.0 , so solution number 3 was selected. There is no optimum value for the shaking rate because the value is still increasing in the range of experimental done. A better result cannot be produced in the shake flask because the liquid inside the flask will be chaotic beyond this point, so the maximum value was chosen. The initial pH of 6.06 was chosen because the intial pH of MCM media was already 6.0 at the initial conditions. The results will clearly deduced the temperature to be $27.8^{\circ} \mathrm{C}$ since the other two solutions have been finalized. So the optimum conditions predicted by the model were shaking rate of $129.8 \mathrm{rpm}$, temperature of $27.8^{\circ} \mathrm{C}$ and $\mathrm{pH}$ of 6.06 (Figure 6). Based on references, a temperature range of $25^{\circ} \mathrm{C}-28^{\circ} \mathrm{C}$ was found to be optimal mycelial growth for most of the Pleurotus species [7] [8]. A researcher used the temperature of $28^{\circ} \mathrm{C}$ for the mycelial cultivation of $P$. flabellatus [9] whilst another also concluded that the temperature range for fruit body development is between $20^{\circ} \mathrm{C}$ and $30^{\circ} \mathrm{C}$ [6]. Islam and coworkers used the temperature range of $25^{\circ} \mathrm{C}-$ $30^{\circ} \mathrm{C}$ for the cultivation of $P$. flabellatus [10]. These evidences supported that there are optimum values of temperature within the range selected.

In order to validate the adequancy of the model equations, verification experiments were carried at the optimized conditions above where $2.45 \mathrm{~g}$ of biomass was produced with the productivity of $980 \mathrm{mg} / \mathrm{litre} / \mathrm{day}$. The small difference between the calculated and experimental data supported the view that the model chosen could be used successfully to optimize biomass production. The average yield of biomass at centre point is $0.937 \mathrm{~g}$. The yield at optimized conditions is higher by approximately 2.7 times than the centre point results.

\begin{tabular}{|c|c|c|c|c|c|c|}
\hline Name & Goal & Lower limit & Upper Limit & Lower weight & Upper weight & Importance \\
\hline Agitation rate & is in range & 50 & 130 & & & \\
\hline Temp & is in the range & 20 & 30 & & & \\
\hline $\mathrm{pH}$ & is in the range & 5 & 7 & & & \\
\hline Mycelial biomass & maximize & 0.07 & 2.54 & & & \\
\hline \multicolumn{7}{|l|}{ Solutions } \\
\hline Number & Agitation rate (rpm) & Temp $\left({ }^{\circ} \mathrm{C}\right)$ & Initial pH & Mycelial biomass (g) & Desirability & \\
\hline 1 & 127.28 & 29.34 & 6.12 & 2.54100 & 1.000 & \\
\hline 2 & 129.00 & 28.82 & 5.40 & 2.55374 & 1.000 & \\
\hline 3 & 129.80 & 27.79 & 6.06 & 2.59871 & 1.000 & Selected \\
\hline 4 & 129.99 & 29.47 & 5.00 & 2.54070 & 1.000 & \\
\hline 5 & 128.81 & 29.71 & 5.50 & 2.59788 & 1.000 & \\
\hline 6 & 129.51 & 29.68 & 5.81 & 2.66600 & 1.000 & \\
\hline 7 & 129.15 & 29.35 & 5.73 & 2.62921 & 1.000 & \\
\hline 8 & 129.92 & 26.94 & 6.10 & 2.55037 & 1.000 & \\
\hline 9 & 128.65 & 29.42 & 6.64 & 2.55794 & 1.000 & \\
\hline 10 & 130.00 & 25.25 & 7.00 & 2.29686 & 0.902 & \\
\hline
\end{tabular}

Figure 5. Showed all the possible solutions from the theoretical model generated by the design expert software. 


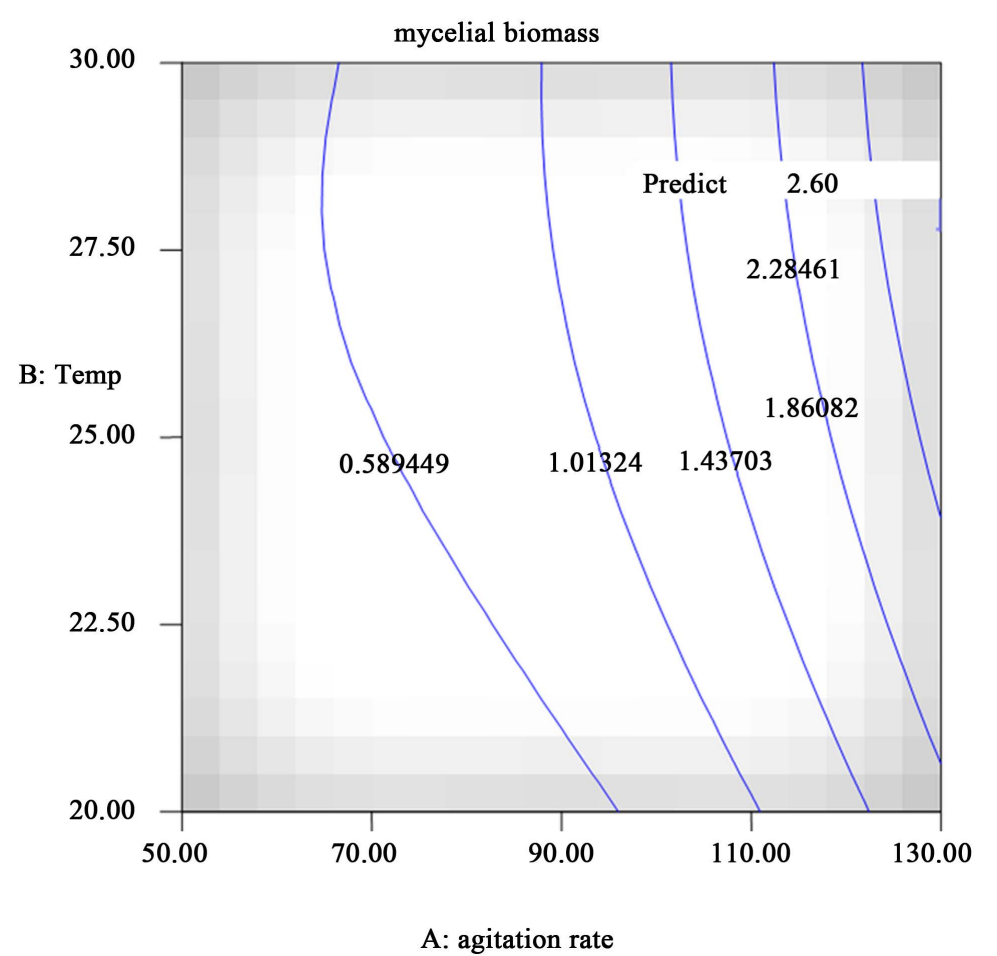

Figure 6. Showed that for the optimum conditions at: agitation rate $129.8 \mathrm{rpm}$ Temperature $27.8^{\circ} \mathrm{C}$, agitation rate and $\mathrm{pH}$ 6.06 , the predicted biomass is $2.60 \mathrm{~g}$.

\section{Conclusion}

$P$. flabellatus biomass production was significantly affected by agitation rate, temperature and the interaction between agitation rate and temperature. Using RSM, biomass production was optimized under these conditions: agitation rate $129.8 \mathrm{rpm}$, temperature $27.8^{\circ} \mathrm{C}$ and $\mathrm{pH} 6.06$.

\section{Acknowledgements}

I would like to thank the staff from Agrotechnology and Biosciences Division, Nuclear Malaysia especially from Bioprocess group Mr Hassan Hamdani Mutaat and Mr Meswan Maskom along with Industrial Biotechnology Research group (KBTI), UKM for their support in this research.

\section{References}

[1] Wasser, S.P. (2002) Medicinal Mushrooms as a Source of Antitumor and Immunomodulating Polysaccharides. Applied Microbiology and Biotechnology, 60, 258-274. http://dx.doi.org/10.1007/s00253-002-1076-7

[2] Zhang, M., Cui, S.W., Cheung, P.C.K. and Wang, Q. (2007) Antitumor Polysaccharides from Mushrooms: A Review on Their Isolation Process, Structural Characteristics and Antitumor Activity. Trends in Food Science \& Technology, 18, 4-19. http://dx.doi.org/10.1016/j.tifs.2006.07.013

[3] Park, J.P., Kim, Y.M., Kim, S.W., Hwang, H.J., Cho, Y.J., Lee, Y.S., Song, C.H. and Yun, J.W. (2002) Effect of Agitation Intensity on the Exo-Biopolymer Production and Mycelia Morphology in Cordyceps militaris. Letters in Applied Microbiology, 34, 433-438. http://dx.doi.org/10.1046/j.1472-765X.2002.01126.x

[4] Shih, I.L., Tsai, K.L. and Hsieh, C. (2007) Effects of Culture Conditions on the Mycelia Growth and Bioactive Metabolite Production in Submerged Culture of Cordyceps militaris. Biochemical Engineering Journal, 33, 193-201. http://dx.doi.org/10.1016/j.bej.2006.10.019

[5] Lee, B.C., Bae, J.T., Pyo, H.B., Choe, T.B., Kim, S.W., Hwang, H.J. and Yun, J.W. (2004) Submerged Culture Conditions for the Production of Mycelial Biomass and Exopolysaccharides by the Edible Basidiomycete Grifola frondosa. Enzyme and Microbial Technology, 35, 369-376. http://dx.doi.org/10.1016/j.enzmictec.2003.12.015

[6] Stamets, P. (2000) Growing Gourmet and Medicinal Mushrooms. 3rd Edition, Ten Speed Press, Berkeley. 
[7] Mehta, K.B. and Bhandal, M.S. (1988) Mycelial Growth Variation of Six Pleurotus Species at Different Temperatures. Indian Journal of Mushroom, 14, 64-65.

[8] Kashangura, C., Hallsworth, J.E. and Mswaka, A.Y. (2006) Phenotypic Diversity amongst Strains of Pleurotus sajor Caju: Implications for Cultivation in Arid Environments. Mycological Research, 110, 312-317. http://dx.doi.org/10.1016/j.mycres.2005.10.006

[9] Lakshmi, S.S. (2013) Comparative Study on Mycelia Growth Rate of Ganoderma lucidum and Pleurotus flabellatus on Agro-Wastes. International Journal of Advanced Research, 1, 199-203.

[10] Islam, M.Z., Rahman, M.H. and Hafiz, F. (2009) Cultivation of Oyster Mushroom (Pleurotus flabellatus) on Different Substrates. International Journal of Sustainable Crop Production, 4, 45-48. 